\title{
Production of Conductive Plastics Using Laminated Coiled Sheet Shaving Method
}

\author{
KANEKO Masao*, JUN Minyoung and YANAGISAWA Akira \\ Department of Mechanical Engineering, Nippon Institute of Technology, \\ 4-1 Gakuendai Miyashiro-machi, Saitama 345-8501,Japan
}

Received 28 January 2005; accepted for publication 25 July 2005

\begin{abstract}
Plastics are basically good insulators of electricity and thus cannot shield against electromagnetic waves. This property causes major problems for humans in our society as well as malfunctions of electronic devices from static electricity. To overcome these problems, production of conductivities plastics is necessary to give to eliminate static electricity, and perform electromagnetic shielding. Pellets mixed with metal fibers, which are currently used in an injection molding process, are produced: metal fibers made by a bundle drawn process are covered with resin by means of extrusion method and then, chopped. This production process has numerous problems such as a complicated process and requires high cost.

In this study, we therefore proposed a laminated coiled sheet shaving method and developed a method of producing pellets mixed with metal fibers at low cost. At the same time, we also conducted investigations on the method of producing conductive plastic sheets using a compression molding, and confirmed that the molded products and the plastic sheets with approximately $10^{-3} \Omega \cdot \mathrm{cm}$ of volume resistivity can be obtained.
\end{abstract}

Key Words : Conductive plastic, Electromagnetic waves, Static electricity, Injection molding, Volume resistivity

\section{積層コイル材切削法による導電性プラスチックの製造}

兼子 正生, 全 敏榮, 柳沢 章

\section{1. 緒言}

プラスチックはもともと電気の良好な絶縁体であるこ とから静電気による電子機器の誤作動の原因となったり, 電磁波を遮蔽出来ず人的な障害問題等社会的に大きな問 題となっている.これらの問題に対し,プラスチックに導 電性を持たせ, 静電気を逃したり電磁波をシールドする必 要がある. プラスチックに導電性を持たせる手法は, プラ スチックポリマー自身に導電性を与える導電性ポリマー や, プラスチック成形体表面に導電性塗料をコーティング するもの, 導電性フィラーをプラスチック中に分散混入す る複合材料的手法等に分類される. 導電性フィラーの混入 は粒子混入, 薄片混入, 繊維混入に分類される[1]. 中で も, 䋐維混入の場合には他のフィラーと比較して, 少ない
混入量で高い導電性を得ることが出来る[2,3]. しかしなが ら, 射出成形に用いられている金属緎維混入ペレットは集 束伸線法による金属繊維を用い,これを押出機により樹脂 被覆した後, 切断して作る.このため, プラスチックと金 属繊維が均一に混合したペレットが得られないという問 題点を持っている. そこで, 本研究では積層コイル材切削 法を用い, 低コストの金属緎維混入ペレット製造法の開発 を行うと共に, この技術を忘用した圧縮成形による導電性 プラスチックシートの製造の研究を行い, 得られた成形体 の導電性に関する検討を行った.

\section{2. 金属淒維混入ペレットの製造}

ここでは, 金属薄板をコイル状に巻き, その端面を切

* 連絡先：日本工業大学機械工学科 345-8501 南埼玉郡宮代町学園台 4-1, E-mail: mkaneko@nit.ac.jp 
削して金属繊維を得るコイル材切削法 [4]の金属繊維製造 技術を応用し，金属繊維混入ペレットの製造を行った. 実 験手順を Fig. 1 に示寸. まず，最初に金属薄板とプラスチ ックシートを積層させながら緎維製造装置の主軸に必要 量巻きつけ, その端面を切削し, プラスチック混合金属緎 維束を製造する. 得られた混合緎維束を加熱引抜き加工し, アスペクト比が 44，48，53，73 になるように切断して金 属繊維混入ペレットの製造を行った.このペレットを用い て射出成形を行い, 得られた成形体の体積固有抵抗值を測 定した.ここでは金属繊維混入ペレットの製造法について 述べる.

\section{1 プラスチック混合金属緟維の製造}

製造条件を Table 1 に示す．供試材として黄銅薄板材 とポリプロピレンシートを用いて, プラスチック混合金属 繊維の製造を行った. 本研究で用いた積層材の場合, 金属 とプラスチックの体積混合比は 1 対 10 となる.この積層 材を巻厚 $\mathrm{W}=20 \mathrm{~mm}$ で製造装置に巻きつけ, この端面を切削 する時に金属とプラスチックが共に良好に切削できる工 具すくい角の検討を行った. 工具すくい角 $\gamma$ は $20^{\circ}$ から $2^{\circ}$ ずつ変化させ, 工具送り量 S は 15〜30 $\mu \mathrm{m} / \mathrm{rev}$ の範囲 で変化させ混合繊維の製造を行った.

\subsection{1 実験結果}

Fig. 2 に積層コイル材切削法により得られたプラスチ ック混合金属繊維束を示す. プラスチック混合金属繊維の 製造実験の結果, すべての送り量で金属とプラスチックが 共に纎維化できるすくい角は $36^{\circ} \sim 38^{\circ}$ であることが確 認された. また，すくい角が $34^{\circ}$ 以下となると金属緎維 のカールが激しくなると共に, プラスチックが粉末状とな り, また, 逆にすくい角が $40^{\circ}$ 以上になるとびびり状態 となり, 良好な連続した繊維の製造が困難となることが確 認された.

次に, 送り量に対する金属繊維の換算直径を調べた結果 をFig. 3 に示す. コイル材切削法で得られる繊維断面は金 属薄板の端面を切削していることから一辺がコイル材の 板厚に一致し, 他の一辺は工具の送り量により決まる長方 形断面となる. そこで, この長方形断面と同一面積の円の 直径を繊維換算直径とした。 すくい角 $36^{\circ}$ ，工具送り量 を $15 \sim 30 \mu \mathrm{m} / \mathrm{rev}$ と変化させた時, 送り量 $15 \mu \mathrm{m} / \mathrm{rev}$ で $40 \mu \mathrm{m}, 30 \mu \mathrm{m} / \mathrm{rev}$ で $55 \mu \mathrm{m}$ の繊維換算直径が得られた.

これから述ベるペレットの製造ならびにプラスチック シートの製造では, コイル材切削法で最も一般的に金属繊 維の製造が行われている工具送り量 $20 \mu \mathrm{m} / \mathrm{rev}$ で得られ る絾維換算直径 $45 \mu \mathrm{m}$ の黄銅繊維を用いることにした.

次に, 得られたプラスチック混合金属繊維束を用いて, 加熱引抜き加工を行い, それを切断して金属繊維混入ペレ ットの製造を行った.ペレットの製造工程ではダイスの引

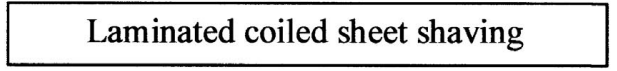

Laminated coiled sheet

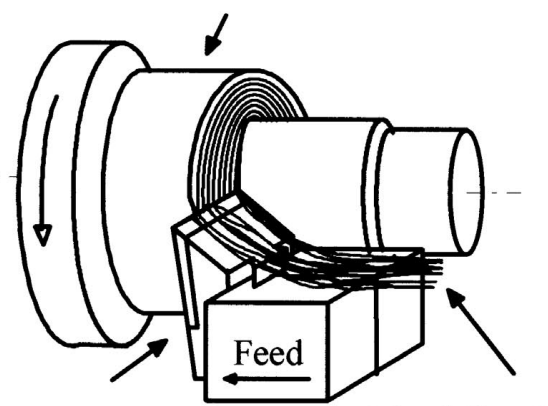

Tool

Metal fiber bundle mixed with plastics

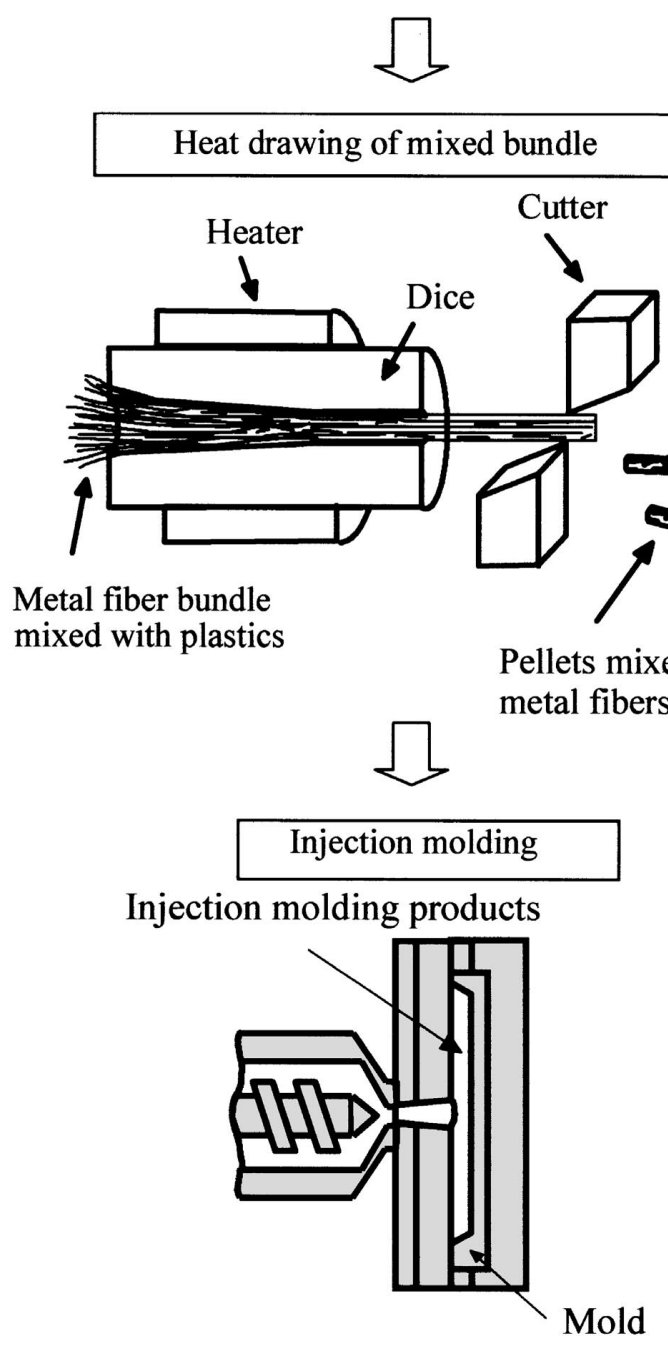

Fig.1 Experimental procedure of conductive plastics production

抜き径 $2 \mathrm{~mm}$ で引抜き速度を $1.5 \mathrm{~m} / \mathrm{min}$ 一定とし, 加熱した 成形ダイスの温度を $423 K \sim 463 K$ まで $5 K$ ずつ変化させ, 良 好に引抜き加工が行えるダイス温度の検討を行った。

ダイス温度 $423 \mathrm{~K} \sim 438 \mathrm{~K}$ ではプラスチックが溶融せず繊 維状態のままとなり，ダイス温度が $443 \mathrm{~K} \sim 448 \mathrm{~K}$ の間では 均一なプラスチックの溶融が得られ, 金属繊維とプラスチ 
Table 1 Experimental conditions

\begin{tabular}{|c|l|}
\hline \multirow{2}{*}{ Work materials } & $\begin{array}{l}\text { Brass }(\mathrm{C} 2680): \mathrm{t}=0.05 \mathrm{~mm} \\
\text { PP sheet }: \mathrm{t}=0.5 \mathrm{~mm}\end{array}$ \\
\hline \multirow{3}{*}{$\begin{array}{c}\text { Cutting } \\
\text { conditions }\end{array}$} & Width of cut $\mathrm{W}: 20 \mathrm{~mm}$ \\
& Fake angle $\quad r: 20 \sim 42^{\circ}$ \\
& Feed rate $\quad \mathrm{S}: 15 \sim 30 \mu \mathrm{m} / \mathrm{rev}$ \\
& Shaving method : Dry cutting \\
\hline
\end{tabular}

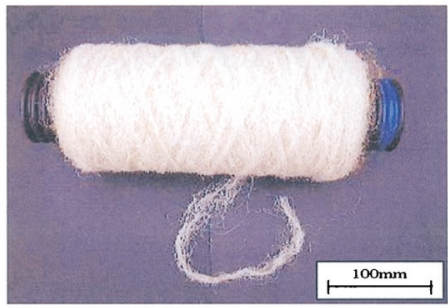

Fig.2 Metal fiber bundle mixed with plastics

ックが均一に混合したペレットが製造可能である.しかし， ダイス温度が $453 \mathrm{~K} \sim 463 \mathrm{~K}$ と高くなるとプラスチックの流 動性が高く黄銅纎維とプラスチックが分離するため均一 なペレットの製造が困難となることが確認された. Fig. 4 にダイス温度 $443 \mathrm{~K}$ で製造したプラスチック混合金属㵶維 束と切断して得られた金属緎維混入ペレットの外観を示 す.

\section{3. 射出成形実験}

\section{1 ペレット寸法条件及び射出成形条件}

得られた金属繊維混入ペレットを用いて射出成形を行 い，成形性，導電性等の検討を行った。ペレットの寸法条 件を Table 2 に示寸. 実際の射出成形では, アスペクト比 (繊維の長さ/繊維の直径) が 60 を超えると繊維がボール 状に固まってしまい（ファイバーボール）射出成形が困難 になると言われている [5]. また, 混入した金属纎維のア

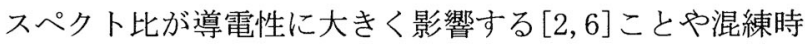
に繊維の折損が大きくなること [3]等を確認している.

本研究ではアスペクト比を 44，48，53，また，金属繊 維とプラスチックとが均一に分散していることを考慮し, さらに高アスペクト比 75 のペレットを製造し，射出成形 を行った．射出成形条件を Table 3 に示す. 射出圧力を $140 \mathrm{MPa}$, 射出率を $57.8 \mathrm{~cm}^{3} / \mathrm{s}$ 一定とし射出成形を行った. さらに Fig. 5 に成形体の形状を示寸.

\section{2 実験結果及び考察}




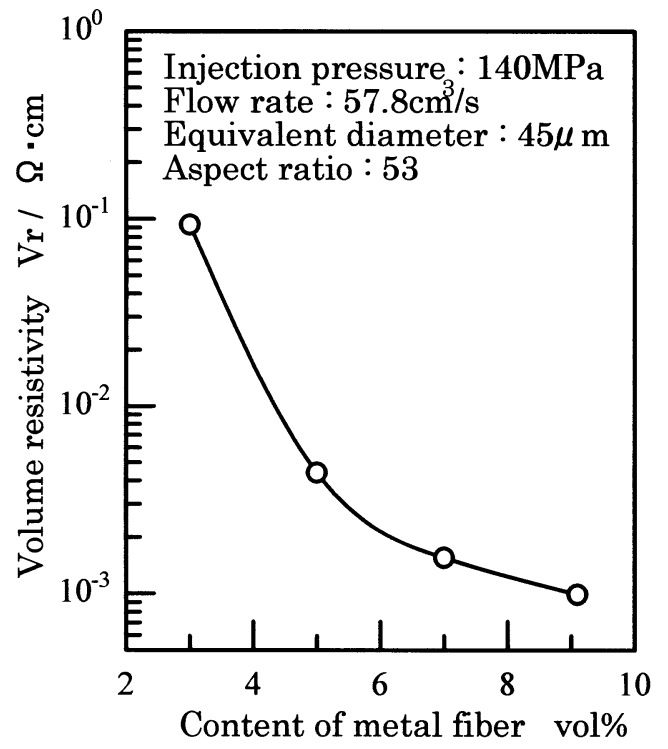

Fig.6 Relation between content of metal fiber and volume resistivity

ットを用い, 繊維混入率を $3 \mathrm{vol} \%$ ～ $\mathrm{vo1} \%$ まで変化させ 射出成形した成形体の体積固有抵抗值の測定を行った. そ の結果を Fig. 6 に示す. 繊維混入率が 3vol\%の場合には $10^{-1} \Omega \cdot \mathrm{cm}$ 程度と高い体積固有抵抗值となったが, 繊維混 入率が $5 \mathrm{vol} \%$ $9 \mathrm{vol} \%$ と大きくなると $10^{-3} \Omega \cdot \mathrm{cm}$ 程度の 低い体積固有抵抗值を示すことが確認された.

次に, アスペクト比を変化させた時の体積固有抵抗值の 測定を行った。 その結果を Fig. 7 に示寸. 緎維混入率が $3 \mathrm{vol} \%$ と $5 \mathrm{vol} \%$ と少ない場合には，アスペクト比が大き くなると体積固有抵抗值の低下がやや大きくなっている が，緎維混入率が $7 \mathrm{vol} \%$ と $9 \mathrm{vol} \%$ と混入量が大きくなる に従い，体積固有抵抗值はアスペクト比に依存せず，ほぼ 一定な值となることが確認された。これは, 緎維混入率が 少ない場合はアスペクト比が大きい方が, すなわち緎維長 さが長いほど繊維の接触点が多くなるためと考えられる. また，繊維混入率が $9 \mathrm{vol} \%$ と多い場合には，アスペクト 比が 44 と小さくても繊維同士が十分に接触できる混入量 であるために, アスペクト比の違いによる体積固有抵抗值 の変化が少なくなったものと考えられる.

次に，射出成形における射出率を変化させた時の体積 固有抵抗値の測定結果を Fig. 8 に示す. いずれの場合も射 出率による体積固有抵抗值の変化は認められず, 射出率に 左右されないことが確認された.これは, 本実験の範囲内 の射出率では樹脂の流動速度に影響されず, 安定した射出 成形が行える事を意味していると考えられる.

\section{4. 導電性プラスチックシート製造実験}

本実験は, 積層コイル材切削法で得られたプラスチック 混合金属繊維から不織布の製造法[7]を利用して, 導電性

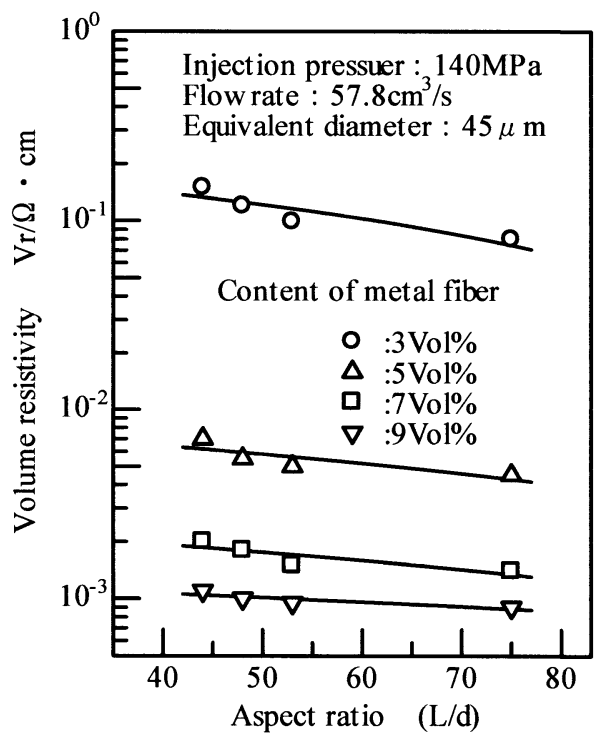

Fig. 7 Relation between aspect ratio and volume resistivity

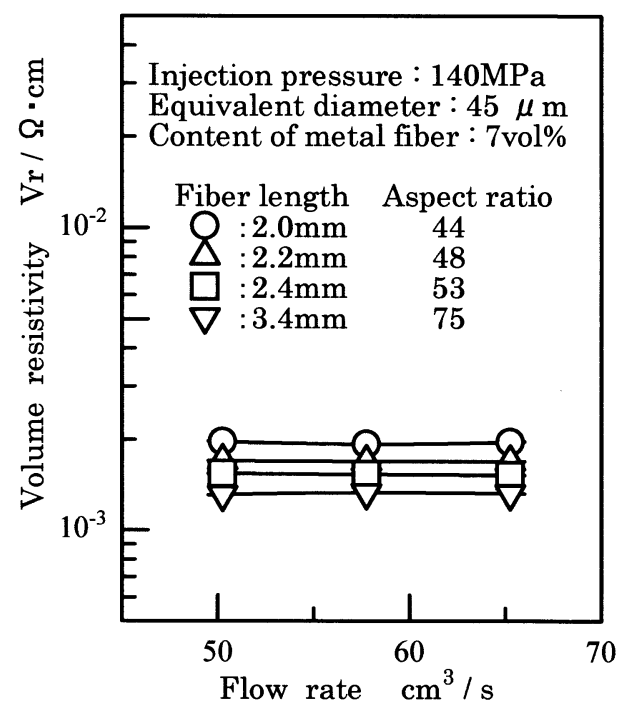

Fig. 8 Relation between flow ratio and volume resistivity

プラスチックシートを製造する．この方法は，金属繊維を 長繊維のまま使用できることから, 射出成形体より大きな 導電性が得られる可能性があり, また, このシートを用い 種々の成形を行う事によって導電性成形品の製造に応用 可能であることが期待される.

\section{1 実験方法}

まず, 初めに得られたプラスチック混合金属繊維を用い, 不織布製造装置により不織布の製造を行った.この方法は, コイル材切削金属繊維用に開発されたもので, 速度比の異 なる中間ロールで繊維を部分的に切断し, 高速回転する切 
断ロールで完全に切断し, エアブローによりコンベアー上 に無配向に積層し，不織布とする方法である．また，この 方法で得られる繊維切断長さは, 中間ロールと切断ロール のロール中心間距離にほぼ比例し，この中心間距離を変え ることにより任意の緎維切断長さを得ることができる. 本 実験では, 繊維切断長さを $5,20,50,100 \mathrm{~mm}$ として不織布の 製造を行った。また，緎維切断長さ $5,20 \mathrm{~mm}$ は装置の関係 上, 手動による裁断とした. 次に, 得られた不織布を Fig. 9 に示すホットプレス加工で成形し, 金属繊維混入導電性プ ラスチックシートとして導電性の評価を行った. また, シ 一ト成形条件を Table4 に示す，大きさを $120 \times 120 \mathrm{~mm}$, 目 付量を $150,300,600 \mathrm{~g} / \mathrm{m}^{2}$ の不織布を製造し，この不織布を 成形圧力 $5,10 \mathrm{MPa}$ とし, 成形温度を $553 \mathrm{~K}$, 成形時間を $60 \mathrm{~s}$ でシートの成形を行った.

\section{2 実験結果及び考察}

金属繊維混入量 $9 \mathrm{vol} \%$ で得られた不織布をホットプレ ス加工した金属繊維混入プラスチックシートを Fig. 10 に 示す.また，ホットプレス加工して得られたシートの目付 量と体積固有抵抗值の関係を Fig. 11 に示す. ホットプレ ス加工されたシートの体積固有抵抗值は繊維長さが長く, 目付量が多くなるほど低くなり繊維長さ $100 \mathrm{~mm}$, 目付量 $600 \mathrm{~g} / \mathrm{m}^{2}$ で $1.5 \times 10^{-4} \Omega \cdot \mathrm{cm}$ の導電性のシートが得られるこ とが確認された.また, 繊維長さ $100 \mathrm{~mm}$ では目付け量によ る大きな変化が認められなかった. 㵶維長さが $100 \mathrm{~mm}$ と長 くなると少ない目付け量でも䋊維の接触点が得られるた めであると考えられる. また, 繊維長さが小さいものでも 目付量が多くなると金属纎維の本数が多くなり, 䋐維の接 触点が増加するため体積固有抵抗值が低くなったものと 考えられる。

さらに, ホットプレス加工したシートの体積固有抵抗值 は本研究で行った射出成形体よりも 1 桁小さな体積固有 抵抗值となることが明らかとなった.

次に,このホットプレス加工して得られたシートを用い て種々の形状に成形される場合, シートは種々の角度に折 り曲げ加工されることが予想されることから, シートの折 り曲げ加工よる体積固有抵抗值の変化を調べた. その結果 をFig. 12 に示す. 纎維長さ $5 \mathrm{~mm}$ と短い場合，折り曲げ角 度 $120^{\circ}$ で僅かに体積固有抵抗値が高くなる傾向を示し たが，繊維長さ $20 \mathrm{~mm}$ 以上の場合には折り曲げ角度 $120^{\circ}$ でも体積固有抵抗值の変化は認められなかった. 䋐維長さ が短くなると, 折り曲げを行った際に内部で金属繊維のズ レが生じ, 繊維同士の接触点が少なくなるためであると考 えられる。

\section{3 㮏電性プラスチックシートを用いた 圧縮成形体}

得られた導電性プラスチックシートを用いて，加熱圧縮

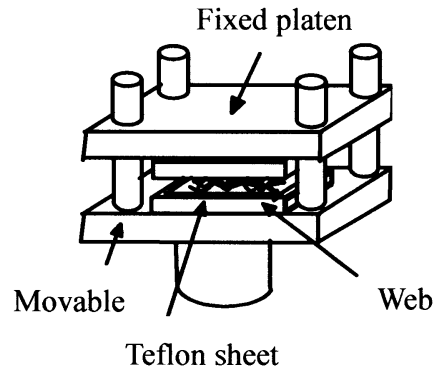

Fig. 9 Production method of the conductive plastic sheet

Table 4 Compression molding conditions

\begin{tabular}{|l|l|}
\hline Web size & $120 \times 120 \mathrm{~mm}$ \\
\hline Weight & $150,300,600 \mathrm{~g} / \mathrm{m}^{2}$ \\
\hline Compression pressure & $5,10 \mathrm{MPa}$ \\
\hline Compression temperature & $553 \mathrm{~K}$ \\
\hline Holding time & $60 \mathrm{~s}$ \\
\hline Content of metal fiber & $9 \mathrm{vol} \%$ \\
\hline
\end{tabular}

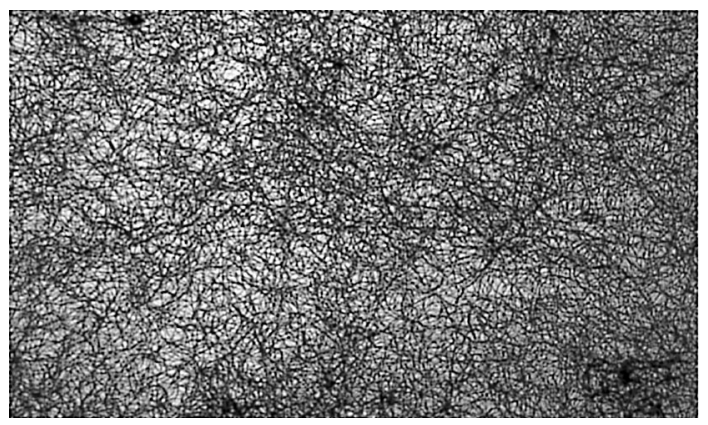

Fig.10 Compression molding sheet

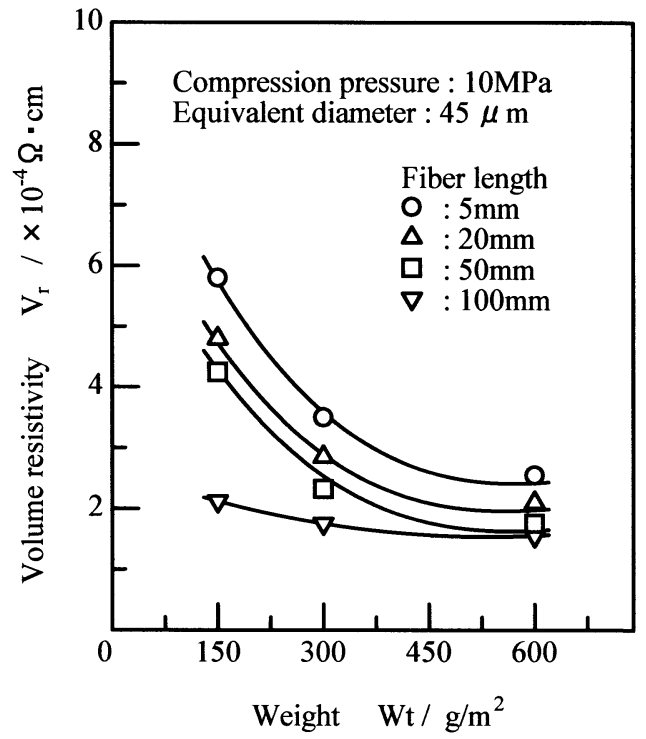

Fig. 11 Relation between weight and volume resistivity of conductive plastic sheet 
成形した例を Fig. 13 (a)，(b)に示す.（a)は繊維切断長さ $50 \mathrm{~mm}$ の不織布を数十枚重ね合わせ, 円柱状に加熱圧縮成 形した後, その一部を切削加工したものである.また，(b) は緎維長さ $50 \mathrm{~mm}$ の不織布を加熱圧縮成形して得られたシ 一トを用いて深皿状に再度加熱圧縮成形したものであり， その切断面においてはどの部分でも導電性を示したが, 成 形体表面では表皮効果により導電性が得られなかった。し かし, その表面を僅かに研磨することにより全ての面で導 電性が得られることが確認された.このように導電性を保 持したまま形状加工できることから, 種々のプラスチック 製品への応用が期待される.

\section{5. 結言}

積層コイル材切削法で得られたプラスチック混合金属 纎維を用い, 金属繊維混入プラスチックの導電性を調べた 結果，次のことが明らかになった。

(1)本研究で提案した積層コイル材切削法を用いた金属㵶 維混入ペレットの製造工程では, 従来の製造工程に比べ, 金属繊維とプラスチックが均一に混合した繊維束が得 られ, 繊維製造と同時にダイスによる溶融固化と切断が 可能であり，より低コストで金属繊維混入ペレットが製 造できる。

(2)得られた金属㵶維混入ペレットを用いて, 射出成形を行 つた結果, 繊維混入率が $9 \mathrm{vol} \%$ の射出成形が可能で $10^{-3}$ $\Omega \cdot \mathrm{cm}$ 程度の体積固有抵抗值を持つ導電性プラスチッ ク成形体の製造が可能である.

(3)加熱圧縮成形した金属緎維混入導電性プラスチックシ 一トは $10^{-4} \Omega \cdot \mathrm{cm}$ 程度の体積固有抵抗值を示し, この プラスチックシートは $30 \sim 120^{\circ}$ まで折り曲げても体 積固有抵抗值の大きな変化は認められず, 各種形状の成 形用シートとしても使用可能である.

\section{References}

[1] Nakagawa, T., Yanagisawa, A.; Sen-i Gakkaishi, 42, p44 (1986)

[2] Yoshino, K., Sakamoto, R.; Japan plastics, 50, p59 (1999)

[3] Yanagisawa, A., Nakagawa, T.; Material Technology, 3, p134 (1985)

[4] Kaneko, M., Yanagisawa, A., Nakagawa, T.; ISSN, 62 , 110 (1996)

[5] Yanagisawa, A., Koyama,H., Suzuki, K., Nakagawa, T.; Composite Materials Symposium, p69 (1984)

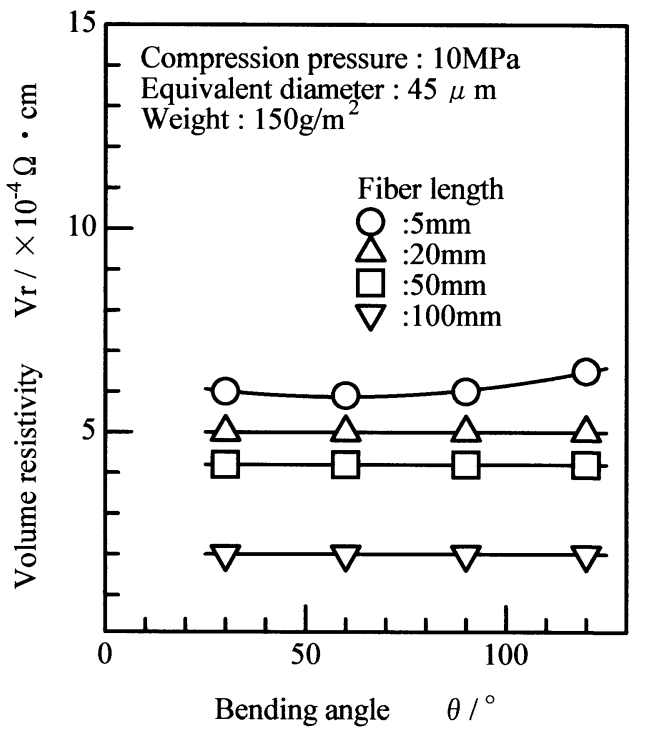

Fig. 12 Relation between bending angle and volume resistivity of conductive plastic sheet

( a )
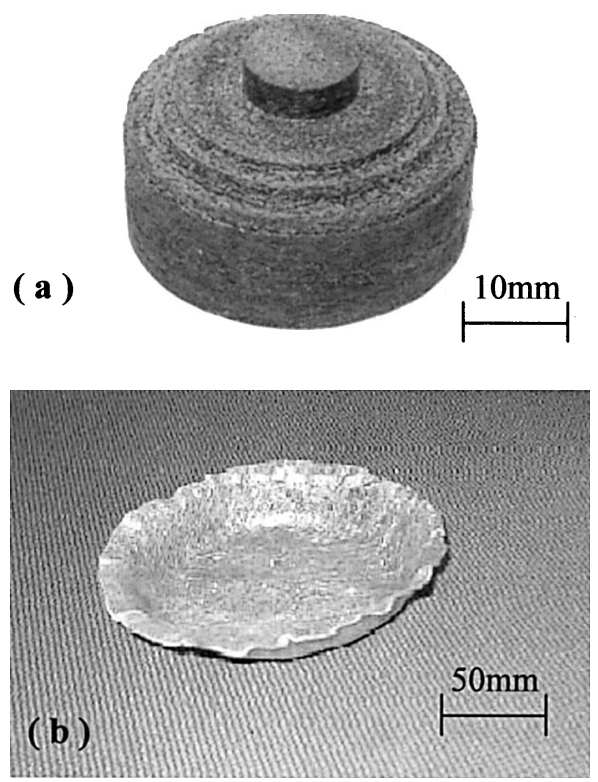

Fig. 13 Compression molding products

[6] Kaneko, M., Yanagisawa, A.; EMC, 55, p78 (1992)

[7] Kaneko, M., Yanagisawa, A., Nakagawa, T.; J.Text. Mach.Soc.Japan, 44, T260 (1996) 